\title{
Human factors and road safety
}

\section{Overview of research at the University of Michigan Transportation Research Institute between 1977 and 1986}

\author{
M. Sivak
}

The University of Michigan Transportation Research Institute, Ann Arbor, Michigan 48109-2150, USA

This article presents a brief overview of the research performed at the Human Factors Division of The University of Michigan Transportation Research Institute between 1977 and 1986. The focus of the research has been on human factors (ergonomics) aspects of road safety. Specifically, the research has dealt with the following issues: vehicle headlighting, vehicle rear lighting and signalling, vehicle displays and controls, vehicle components, conspicuity of vehicles, legibility of traffic signs and licence plates, driver reaction time, driver performance, stopping sight distance, driver seated position, individual differences (drivers with disabilities, older drivers), methods for measuring blood alcohol concentration, societal violence and traffic accidents, cross-cultural comparison of driver risk-perception, and theoretical issues.

Keywords: Road safety, vehicle design, driver performance

\section{Introduction}

This article summarises recent research at the Human Factors Division of the University of Michigan Transportation Research Institute (UMTRI), formerly named Highway Safety Research Institute (HSRI).

The Human Factors Division is currently operating with a $\$ 450,000$ per year research budget. The staff consists of three PhD scientists, several research assistants and a secretary. The primary researchers - all human factors specialists - are trained in experimental and industrial psychology, industrial and operations engineering, and statistics. Excellent support is provided by the Institute, including an electronics shop, laboratory space and equipment, library and computer services.

The research activities of the Human Factors Division have concentrated on the safety aspects of operating vehicles. The wide range of problems investigated have included those that are driver-centred (e g, drivers with disabilities and elderly drivers, driving-test development), vehicle-centred (e g, vehicle lighting and signalling, instrument-panel controls and displays), and environment-centred (e g, legibility of traffic signs). In examining these issues, various experimental approaches have been used, including computer-controlled laboratory studies, on-the-road monitoring of drivers' manoeuvres and eye movements, computer simulations, and analyses of accident statistics.

\section{Vehicle headlighting}

A 1977 report (Olson, 1977) discusses the historical development of automobile headlighting and describes the differences between European and American concepts in terms of construction and light output/distribution. The advantages and disadvantages of each system are described.
The report also contains an extensive annotated bibliography (65 publications). A more recent review (Perel et al, 1983) describes major research findings and major issues in contemporary headlighting.

In the late 1970 s, a research project dealt with the feasibility of a single-beam headlighting system (HalsteadNussloch et al, 1979). As part of this project, field evaluations and computer simulations of alternative systems were performed. The results indicated that the experimental single beams provided only marginal and situation-specific improvements over the standard US low beams.

Olson and Sivak (1983c) dealt with possible improvements to the US low-beam system. This research consisted of laboratory and field experiments, and computer modelling. Based on the results of this research, recommendations were made for changes to the low-beam specifications. This extensive research formed the basis for several journal and SAE publications. These publications concentrated on the effects of foreground illumination (Olson and Sivak, 1983a), comparison of headlamp visibility distances with stopping distances (Olson and Sivak, 1983b), discomfort glare from on-coming vehicles (Olson and Sivak, 1984a), discomfort and disability glare from automobile rear-view mirrors (Olson and Sivak, 1984c), and re-analysis of some past glare and illumination findings (Olson and Sivak, 1984b).

A range of issues relevant to evaluating visibility provided by automobile headlamps was reviewed by Sivak and Olson (1985a). In addition to discussing general issues, this report focused on the driver visibility model DETECT (developed by the Ford Motor Company). It was argued that further progress in the development of headlighting models and their increased acceptability is contingent on reaching a consensus regarding what good headlighting should be able to do. Consequently, the report recommended a worldwide 
survey of experts in industry, academia and government on desirable aspects of headlamp performance.

In a related research project, Olson (1982) studied headlighting beam-aim variance associated with replacement of burned-out lamps without re-aim. Both US-type sealed beams and European-type replaceable-bulb units were tested. The results indicated that European-type units were less variable in their vertical aim, while US-type units were less variable in their horizontal aim.

Motorcycle/moped headlighting was the topic of another research project (Olson and Abrams, 1982). Following several field experiments and computer simulations, an improved motorcycle/moped low-beam headlighting system was recommended.

Much of the UMTRI headlighting research used a computer program developed in the early 1970s (Mortimer and Becker, 1973; Becker and Mortimer, 1974). This program predicts seeing-distance for various targets as a function of the headlamps selected, their location and aim, target position and several other variables. Green (1980) prepared supplemental information on how to run an updated version of this program.

\section{Vehicle rear lighting and signalling}

The literature on automobile rear lighting and signalling was reviewed in two reports. Sivak (1978) focused on the effects of colour, intensity, position and spacing of rear lights. This report also contains an annotated bibliography (36 publications). A more recent and comprehensive review (Henderson et al, 1983) dealt with both the findings and issues in rear lighting and signalling.

Sivak, Flannagan et al (1986) performed a series of laboratory and field studies concerning brake-lamp photometric requirements. Specifically, these studies investigated brake-signal detection under high ambient illumination, and differentiation between brake and presence signals under low levels of ambient illumination. On the basis of these studies, it was recommended that luminous intensity be retained as the relevant photometric parameter of automobile brake lamps, and $80 \mathrm{~cd}$ be retained as the minimum brake-lamp luminous intensity.

The potential benefits of supplemental high-mounted brake lights were investigated in three studies that were performed in actual traffic. In the first study, Sivak, Post et al (1981a) measured reaction times of alerted drivers to brake signals presented by one of 22 configurations of brake lights. The next two studies evaluated responses of unalerted drivers to supplemental high-mounted brake lights: Sivak, Post et al (1981b) used a photographic technique to measure frequency and delay of brake responses, while Sivak, Olson and Farmer (1981) used radar to measure frequency and delay of speed-change responses. The evidence from these three studies is inconclusive as to the benefit of the highmounted brake lights.

Sivak, Conn and Olson (1986) evaluated the distribution of driver eye fixations when following other vehicles. The aim was to describe the areas of the forward field of view that are most frequently fixated. Such information is important for selecting optimal locations for automobile brake lights: brake lights that are closer to eye fixations are likely to result in shorter driver reaction times than brake lights farther away from the eye fixations. The results indicated that, under the conditions of this study, eye fixations tended to concentrate in the rear-window area of the lead car and not in the area of the standard low-mounted brake lights. These results provide a possible behavioural explanation for the accident reductions found with highmounted brake lights in previous field studies.

Post (1978) reviewed the special considerations regarding lighting and signalling for emergency, school bus and service vehicles. The report contains a review of available hardware, review of basic and applied vision research, analysis of signalling requirements, and recommendations.

\section{Vehicle displays and controls}

Green and Burgess (1980) and Gingold et al (1981) reported on two experiments dealing with the development and evaluation of candidate pictographic symbols for motorvehicle displays and controls. In Green and Burgess (1980) college students served as subjects, while truck drivers were used in the Gingold et al (1981) study. In the first parts of both experiments, subjects drew pictures intended to identify truck controls and displays. These suggestions, along with others generated by experts, were subsequently rated by subjects in terms of their meaningfulness. Based on these ratings, recommendations were made for new international symbols.

Speedometers and tachometers were the topic of research by Green (1983). The subjects in this computer-controlled survey answered questions on the frequency and conditions affecting the usage of these displays.

Green (1984) studied driver understanding of fuel and engine gauges. The method involved asking about specifications for their own vehicles, and responding to slides of instrument clusters. The data showed that (1) many drivers knew little about their vehicles; (2) for engine functions, drivers were more likely to understand moving pointers than numeric displays; (3) pointer alignment, colour-coding, and labelling the normal zone all greatly improved understanding of engine displays; and (4) drivers understood all of the existing labelling schemes for analogue fuel displays but had varying levels of difficulty with digital fuel displays.

A study by Miller et al (1984) investigated the effects of various screen filters on specular reflection from CRT displays and on user performance. The results indicated that a micromesh filter reduces specular reflection. However, there were no statistically significant improvements in the speed or accuracy of CRT users. (Although this study was performed in the context of indoor usage of CRTs, it is of interest here because of the utilisation of CRT displays in some of the current automobiles.)

Green (1979) addressed the topic of automobile multifunction stalk-mounted controls. The report contains a comprehensive literature review (covering 20 major documents), detailed descriptions of the stalk controls in 1977-79 model-year cars, as well as human factors analyses and recommendations concerning stalk control design.

\section{Vehicle components}

Effects of windshield damage on driving safety were studied by Green and Burgess (1981). The report summarises a literature review, accident-data analysis, and a laboratory experiment. The results of the computer-controlled 
laboratory experiment indicate that interposing a severely damaged windshield between a driver and a simulated night driving scene significantly increases the time it takes to make braking decisions. This effect was especially pronounced in the presence of a light simulating the glare of an oncoming vehicle's headlights.

Olson (1985a) evaluated the effects of various interior lighting systems on driver sight distance at night. A new lighting system, in which the light sources were contained in the rearview mirror, was compared with the standard system and a control (no lights) in three different vehicles for both forward and rearward visibility. The results indicated that turning on the interior lights could reduce forward sight distance by as much as $20 \%$, with the effect more pronounced for rearward sight distance. The new lighting system was better than the standard system in two of the three cars for forward sight distance, and better in all three cars for rearward sight distance.

Olson and Bender (1986) measured reflections on the inside of windshields of several different buses. Two types of data were collected. First, measurements were made of the luminance of the reflections at a large number of points on the windshield from a 50th percentile driver's eye height. Second, equivalent veiling luminance measurements were made from various driver eye heights, both for straightahead and right-turn conditions, and with different types and levels of interior lighting.

Olson and Winkler (1985) surveyed the conditions of lighting equipment, rearview mirrors, and tyres in a nationwide sample of vehicles in use. The major findings for vehicles manufactured between 1979 and 1984 were as follows: (1) about $60 \%$ of the vehicles had one or more low-beam units aimed outside SAE limits, (2) the rearview mirrors were generally in good physical condition, and provided a reasonably good view of important areas to the rear, and (3) about $10 \%$ of the tyres were found to have a defect (the most frequent defect being uneven wear), and the average tread depth (except for new cars) was 0.2 in $(5 \mathrm{~mm})$.

\section{Conspicuity of vehicles}

Olson (1984) reviewed accident data and experimental studies related to the conspicuity of motorcycles. In an experimental study, Olson, Halstead-Nussloch and Sivak (1981) evaluated a range of day time and night-time treatments for improved front conspicuity of motorcycles. Using as subjects unalerted drivers in actual traffic, several treatments were shown to increase motorcycle conspicuity. Specifically, daytime conspicuity was improved when the low-beam headlamp was turned on, when the high-beam headlamp was turned on and modulated in intensity three times per second, or when the motorcyclist wore a fluorescent vest and helmet cover. Night-time conspicuity was improved when the motorcycle used additional running lights, or when the motorcyclist wore a retro-reflective vest and helmet cover.

In a related study, Green, Kubacki et al (1979) investigated the night-time conspicuity of tractor-semitrailers The study included accident analyses, a literature review, and a small-scale eye-movement evaluation of treatments for increased side and rear conspicuity. Two main findings emerged. First, despite the large size of tractor-semitrailers, they are difficult to see at night, as evidenced by the high frequency of accidents where they are struck in the side or rear. Second, the addition of even a small strip of retroreflective material can significantly increase their night-time conspicuity.

\section{Legibility of traffic signs and licence plates}

Night-time legibility of traffic signs was the subject of several research projects. Olson and Bernstein (1979) found that highly reflective sign backgrounds permit somewhat greater legibility distances, and that reflective backgrounds reduce the effects of changes in viewing conditions. The results of a follow-up study by Olson, Sivak and Egan (1983) indicated that (1) legend luminance contrast is the most important variable in night-time sign legibility; (2) there is a relatively narrow range of optimal contrast; and (3) as background luminance increases, legibility improves and legend contrast requirements decrease.

Sivak, Olson and Pastalan (1981) and Sivak and Olson (1982) investigated the effects of driver's age on night-time sign legibility. In the study by Sivak, Olson and Pastalan (1981), younger and older subjects were matched in terms of their high-luminance (daytime) visual acuity. The subjects drove or were driven towards a sign. The results indicated that the legibility distances for the older subjects were $65-$ $77 \%$ of those for the younger subjects. In a follow-up study (Sivak and Olson, 1982) the age differences in legibility distances were eliminated by equating younger and older subjects in terms of their low-luminance (night-time) visual acuity. Additionally, this study showed that glare sources positioned outside of the fovea might, under certain conditions, improve night-time legibility.

Optimal and minimal luminance characteristics for retroreflective highway signs were the topic of a review by Sivak and Olson (1985b). The review of the applied sign-legibility research formed the basis for luminance recommendations. These luminance recommendations, in turn, were used in a computer model of sign legibility to obtain the recommended retro-reflectance values.

Night-time legibility of licence plates was investigated by Olson and Sivak (1983d). The results of this field study indicated a general superiority for fully reflectorised licence plates, especially under conditions of glare. The older subjects, in particular, seemed to benefit from the highly reflective plates.

\section{Driver reaction time}

An important by-product of the high-mounted-brakelight studies was the accumulation of extensive data on intraffic reaction times of unalerted drivers to brake signals from a vehicle immmediately ahead (Sivak, Post et al, 1981 a, 1981 b; Sivak, Olson and Farmer, 1981). The most extensive of these data sets is summarised in Sivak, Olson and Farmer (1982).

Olson and Sivak (1986) evaluated reaction time of unalerted drivers to an obstacle in their lane while cresting a hill. The results indicated a 95 th percentile driver reaction of about $1.6 \mathrm{~s}$. Interestingly, this finding was obtained for both younger and older drivers. 


\section{Driver performance}

The purpose of a study by Olson, Butler et al (1982) was to develop a battery of low-speed driving tests that could be used for preliminary systems screening of drivers, vehicles and components. Several driving tests were developed, together with suitable performance measures. These tests were administered to a group of subjects, and the data were subjected to a factor analysis. Six factors emerged, with one or more tests under each. These results indicated that a test battery can be created using a small number of tests, in a relatively confined space and without elaborate instrumentation, and still sample several relevant drivingskill dimensions.

Olson, Zimmer and Pezoldt (1986) evaluated the performance of naive drivers in negotiating road edge drops. The independent variables included height and shape of the road edge drop, vehicle size, front- or rear-vehicle drive, softness of the verge (shoulder) of the road, and speed. The results of this study, together with other available data, indicate that road edge drops pose a considerable hazard to drivers who attempt recovery from a position where the wheels of the car hang up (scrub) along the vertical edge of the road. However, rounded or bevelled road edges seem greatly to reduce the hazard.

Green, Gillespie et al (1984) studied subjective preferences of steering assistance levels. The results indicated that drivers wanted the assistance levels to decrease with speed. Furthermore, the desired assistance levels for a sports car were lower than for a family saloon.

Green (1985) assessed the effectiveness of a prototype driver-alertness device that measures driver reaction time to a tone. The testing was performed very late at night using a driving simulator. The following information was recorded: data on steering error, the interval between heart beats, response time to the device, and experimenter's rating of the subject's alertness. Across sessions, drivers were exposed to four test conditions - device with a fixed interval tone, device with a random schedule, listening to the radio, and control (no device or radio). The results indicated that participants were most alert while listening to the radio, and least alert in the control condition. Of the two versions of the device, the greater level of alertness was associated with the random mode.

\section{Stopping sight distance}

A recent multi-disciplinary project (Olson, Cleveland et al, 1984) dealt with desirable sight distance as related to parameters such as driver reaction time and vehicle stopping distance. As part of this study, literature reviews and original research were conducted on driver eye height, roadway obstacle height, driver reaction time, vehicle braking distance, accident analyses, and mathematical relationships between stopping sight distance and geometric design elements. Based on these investigations, recommendations were made for changes in design driver eye height, design obstacle height and design braking distance.

\section{Driver seated position}

Schneider et al (1979) investigated effects of several anthropometric and vehicular factors on driver seated position. The subjects in this study were tested in six different vehicles for preferred seat position under nondriving and driving conditions. The results indicated that on a total sample basis there was little difference between seat positions selected under non-driving and driving conditions, but that individuals may show significant differences between the two conditions. Additional analyses indicated that stature is the most significant anthropometric variable in determining preferred seat position. Depending on the vehicle, it explained approximately 30 to $60 \%$ of the seat position variance.

\section{Individual differences}

\section{Drivers with disabilities}

A five-year project investigated the interrelations of brain damage, perceptual/cognitive skills, and driving. The results of the first study (Sivak, Olson et al, 1981) indicated that persons with brain damage, as a group, exhibited impaired perceptual/cognitive skills, and impaired driving. However, persons with brain damage who scored well on certain perceptual/cognitive tests tended to show good driving performance as well. An implication of these results is that therapeutic techniques capable of improving the impaired perceptual/cognitive skills may improve driving performance as well.

This implication was experimentally evaluated in two studies (Sivak, Hill et al, 1981, 1984). In these studies, simple paper-and-pencil activities were used as training techniques for perceptual/cognitive deficits. The results suggest that perceptual/cognitive skills of persons with brain damage may be amenable to relatively short-term training, with a transfer of the benefits to driving performance as well.

A pilot study (Sivak, Hill and Olson, 1984) investigated the modifiability of perceptual/cognitive deficits by training which consisted of performing microcomputer-generated video tasks. Based on generally positive results, this study recommended comprehensive evaluation of the potential benefits of this type of training on both perceptual/cognitive skills and driving performance.

In a related area, Olson, Post and Huber (1978) performed a safety evaluation of converted vans for transportation of the disabled and elderly. The report describes a review of the specifications, based upon analysis of crash data as well as upon consultations with manufacturers and organisations using such equipment.

\section{Older drivers}

Driver age was a parameter in several studies that concentrated on other aspects of the vehicle-driverenvironment system. For example, effects of driver age were investigated in the context of vehicle headlighting (Olson and Sivak, 1983c), legibility of traffic signs (Olson, Sivak and Egan, 1983; Sivak, Olson and Pastalan, 1981; Sivak and Olson, 1982), legibility of licence plates (Olson and Sivak, 1983d), driver reaction time (Green and Burgess, 1981; Sivak, Post et al, 1981a; Olson, Cleveland et al, 1984; Olson and Sivak, 1986), and driver risk-perception (Sivak and Soler, 1986b). Some of this research, dealing with night-time visual problems of elderly drivers, was summarised by Sivak and Olson (1984)

\section{Methods for measuring blood alcohol concentration}

Olson (1985b) reviewed the literature concerning the value of two approaches of screening alcohol-impaired drivers: a new field sobriety screening battery incorporating gaze nystagmus, and portable breath testers employing fuel- 
cell technology. It was concluded that while the bulk of the available evidence indicates that both of the screening techniques have merit, further work is needed to try to reduce some of the noted problems and limitations.

\section{Societal violence and traffic accidents}

Sivak (1983) studied the relation of societal violence and other macro-level variables to traffic accidents. In the first of two analyses, multiple regression was applied to 1977 data from each of the 50 US states. Traffic fatalities per registered vehicle was the dependent variable. The main finding was that homicide rates (but not suicide rates) predicted states' traffic fatality rates; additional significant predictors were the proportion of young drivers and the fatality rate from accidents other than those connected with the operation of motor vehicles. These three variables accounted for $68 \%$ of the variance of traffic fatalities. The second analysis successfully validated the predictive power of the two primary predictors (homicides and young drivers). The validation was performed by using 1977 regression coefficients to estimate 1978 traffic fatalities.

\section{Cross-cultural comparison of driver risk-perception}

An ongoing co-operative research project with Spain investigates cross-cultural differences in driver risk-taking. The first in a series of studies (Sivak and Soler, 1986a) involved an analysis of factors associated with traffic accidents in Spain and the USA. The second study (Sivak and Soler, 1986b) investigated differences in risk-perception between Spanish and US drivers. Subjects in this study estimated the risk involved in slides of traffic scenes. The results indicated that the Spanish drivers reported higher level of risk than did the US drivers for the same traffic scenes. Furthermore, certain aspects of the traffic scenes had influence on risk-perception in one but not the other country, suggesting the need for differential emphasis in driver education in the two countries.

\section{Theoretical issues}

Sivak, Olson and Green (1986) discussed human factors methods for evaluating the design of vehicle components. In the first part, the need for himan factors measures was defended on the basis of impracticality of the ultimate measure - the accident rate. In the main part of the paper, several human-performance measures were discussed: intraffic reaction times, driver eye fixations, visibility distances, subjective ratings of discomfort, and driver preferences.

Methodological considerations in evaluation studies were dealt with by O'Day et al (1985). The following topics were discussed in the context of studies evaluating the efficacy of seat-belt laws: existence of a relation (control group, chance variation, robustness of the test, multiple comparisons, reliability of the measure, effects of other variables, sample size), existence of a causal relation (underlying causal relation, interaction with other variables, maturation effects, regression to the mean), validity of the measure, and external validity.

Olson and Sivak (1981) dealt with problems in the detection and identification of significant roadway conditions. The paper discussed the complex, non-automatic and different nature of these two processes. Furthermore, the paper dealt with a range of related issues, such as alerted $v s$ unalerted driver, peripheral vs foveal vision, and capacity limitations of human information processing. An expanded discussion of these issues is contained in Olson and Sivak (1984d).

The general relation of visual perception and driving was discussed in Olson (1986). This article first described the basics of visual perception, and then focused, mainly, on a number of the specific problems relating to both day and night operation of motor vehicles.

In a related article, Olson, Sivak and Henson (1981) discussed headlighting and visibility limitations, especially from the point of view of the danger for pedestrians. This danger, it is argued, is a consequence of the limitations of low-beam headlighting systems, coupled with pedestrians' overestimation of their own visibility.

Sivak (1981a) argued that traditional correlational analyses of human skills and road accidents have not been very productive. Some of the likely reasons for this were discussed. Furthermore, an alternative approach to accident causation was outlined. In this approach the importance of a skill with good face validity to driving is assessed in terms of its sensitivity to frequently occurring transient human states such as fatigue, stress, and alcohol intoxication

Sivak (1981b) briefly summarised current knowledge of how human factors contribute to traffic accidents, and summarised preventive measures motorists can take to minimise their chances of accident involvement.

Sivak (1985) discussed arguments and research evidence concerning multiple ergonomic approaches to problems of transportation safety. Transportation accidents (and their consequences) are the result of multi-factor processes. Therefore, the probability of an accident (and of an injury, given an accident) can be influenced by interventions directed at any of the factors. Furthermore, the most effective accident counter-measures are not necessarily those directed at the 'cause' of accidents. As examples, multiple ergonomic counter-measures were noted for road accidents involving alcohol-intoxicated drivers and elderiy drivers, as well as for minimising injuries resulting from road accidents.

\section{Concluding comments}

This review was intended to provide an indication of the breadth and depth of recent road-safety research at the Human Factors Division of The University of Michigan Transportation Research Institute. The wide variety of topics investigated reflects the diversity and complexity of issues in road safety. The research described in this review has led to a greater understanding of contemporary roadsafety problems, and has offered solutions to many of these problems. The implementation of these solutions, in turn, requires action in the engineering, educational and legislative areas.

\section{References}

Becker, J.M., and Mortimer, R.G.

1974 Further development of a computer simulation to predict the visibility distance provided by headlamp beams. Ann Arbor, Michigan: Highway Safety Research Institute, The University of Michigan, Report No HF-74-26. 
Gingold, M., Shteingart, S., and Green, P.

1981 Truck driver preferences and suggestions for instrument panel symbols. Ann Arbor, Michigan: Highway Safety Research Institute, The University of Michigan, Report No UM-HSRI-81-30.

Green, $\mathbf{P}$.

1979 Automobile multifunction stalk controls: literature, hardware and human factors review. Ann Arbor, Michigan: Highway Safety Research Institute, The University of Michigan, Report No UM-HSRI-79-78.

Green, $\mathbf{P}$.

1980 A computer simulation of headlamp variables and drivers' sight distances: operating instructions. Ann Arbor, Michigan: Highway Safety Research Institute, The University of Michigan, Report No UM-HSRI$80-44$.

Green, $P$.

1983 What do drivers say they use speedometers and tachometers for? Ann Arbor, Michigan: The University of Michigan Transportation Research Institute, Report No UMTRI-83-49.

Green, $P$.

1984 Driver understanding of fuel and engine gauges. Society of Automotive Engineers, Paper No SAE840314.

Green, $\mathbf{P}$.

1985 Human factors test of a driver alertness device. Ann Arbor, Michigan: The University of Michigan Transportation Research Institute, Report No UMTRI$85-49$.

Green, P., and Burgess, W.T.

1980 Debugging a symbol set for identifying displays: production and screening studies. Ann Arbor, Michigan: Highway Safety Research Institute, The University of Michigan, Report No HSRI-80-64.

Green, P., and Burgess, W.T.

1981 Windshield damage and driving safety. Ann Arbor, Michigan: Highway Safety Research Institute, The University of Michigan, Report No UM-HSRI-81-35.

Green, P., Gillespie, T., Reifeis, S., Wei-Haas, L., and Ottens, D.

1984 Subjective evaluation of steering efforts levels. Ann Arbor, Michigan: The University of Michigan Transportation Research Institute, Report No UMTRI84-39.

Green, P., Kubacki, M., Olson, P.L., and Sivak, M.

1979 Accidents and the night-time conspicuity of trucks. Ann Arbor, Michigan: Highway Safety Research Institute, The University of Michigan, Report No UM-HSRI-79-92.

Halstead-Nussloch, R., Olson, P.L., Burgess, W.T., Flannagan, $M$., and Sivak, $M$.

1979 Evaluation of the feasibility of a single-beam headlighting system. Ann Arbor, Michigan: Highway Safety Research Institute, The University of Michigan, Report No UM-HSRI-79-91.

Henderson, R.L., Sivak, M., Olson, P.L., and Elliott, W.M. 1983 Motor vehicle rear lighting and signaling. Society of Automotive Engineers, Paper No SAE-830565.
Miller, D.E., Peterson, E.A., and Green, P.

1984 Comparison of CRT anti-reflection filters. Ann Arbor, Michigan: The University of Michigan Transportation Research Institute, Report No UMTRI-84-8.

Mortimer, R.G., and Becker, J.M.

1973 Development of a computer simulation to project the visibility distance provided by headlamp beams. Ann Arbor, Michigan: Highway Safety Research Institute. The University of Michigan. Report No HF-73-15.

O'Day, J., Sivak, M., Wagenaar, A.C., and Haney, J.E.

1985 The UMTRI Research Review, 16.1, 1-8. Seat-belt laws: Traps to avoid in evaluation studies.

Olson, P.L.

1977 The relative merits of different low beam headlighting systems: a review of the literature. Ann Arbor. Michigan: Highway Safety Research Institute, The University of Michigan, Report No UM-HSRI-77-55.

Olson, P.L.

1982 The effect of headlamp bulb replacement on unit aim: a comparison of SAE and ECE systems. Ann Arbor, Michigan: Highway Safety Research Institute, The University of Michigan, Report No UM-HSRI82-3.

Olson, P.L.

1984 Motorcycle conspicuity. In: G.A. Peters and B.J. Peters (Eds), Automotive Engineering and Litigation, Vol 1. New York: Garland.

Olson, P.L

1985a The effect of vehicle interior lighting systems on driver sight distance. Ann Arbor, Michigan: The University of Michigan Transportation Research Institute, Report No UMTRI-85-31.

Olson, P.L.

1985b Measurement of blood alcohol concentration in Michigan drivers. Ann Arbor, Michigan: The University of Michigan Transportation Research Institute, Report No UMTRI-85-52.

Olson, P.L.

1986 Visual perception. In: I.S. Kuperstein and N.L. Salters (Eds), Attorney's guide to engineering, Vol 3. New York: Matthew Bender.

Olson, P.L., and Abrams, R.A.

1982 Improved motorcycle and moped headlamps. Ann Arbor, Michigan: Highway Safety Research Institute, The University of Michigan, Report No UM-HSRI$82-18$

Olson, P.L., and Bender, M.

1986 Photometric measurement of bus windshield light reflection arising from bus interior light sources. Ann Arbor, Michigan: The University of Michigan Transportation Research Institute, Report No UMTRI-86-6-9.

Olson, P.L., and Bernstein, A.

1979 Human Factors, 21, 145-160. The night-time legibility of highway signs as a function of their luminance characteristics.

Olson, P.L., Butler, B.P., Burgess, W.T., and Sivak, M.

1982 Toward the development of a comprehensive driving test: low-speed maneuvering. Ann Arbor, Michigan: 
Highway Safety Research Institute, The University of Michigan, Report No UM-HSRI-82-4.

Olson, P.L., Cleveland, D.E., Fancher, P.S., and

Schneider, L.W.

1984 Parameters affecting stopping sight distance. Ann Arbor, Michigan: The University of Michigan Transportation Research Institute, Report No UMTRI84-15.

Olson, P.L., Halstead-Nussloch, R., and Sivak, M.

1981 Human Factors, 23, 237-248. The effect of improvements in motorcycle/motorcyclist conspicuity on driver behavior.

Olson, P.L., Post, D.V., and Huber, M.

1978 Safety evaluation of vehicles used to transport the handicapped and elderly. Ann Arbor, Michigan: Highway Safety Research Institute, The University of Michigan, Report No UM-HSRI-78-25.

Olson, P.L., and Sivak, M.

1981 Problems in the detection and identification of significant roadway conditions. Ann Arbor, Michigan: Highway Safety Research Institute, The University of Michigan, Report No UM-HSRI-81-46.

Olson, P.L., and Sivak, M.

1983a Perceptual and Motor Skills, 57, 1036-1038. Automotive headlighting: effect of foreground illumination.

Olson, P.L., and Sivak, M.

1983b Perceptual and Motor Skills, 57, 1177-1178. Comparison of headlamp visibility distance and stopping distance.

Olson, P.L., and Sivak, M.

1983c Improved low-beam photometrics. Ann Arbor, Michigan: The University of Michigan Transportation Research Institute, Report No UMTRI-83-9.

Olson, P.L., and Sivak, M.

1983d Night-time legibility of license plates. Ann Arbor, Michigan: The University of Michigan Transportation Research Institute, Report No UMTRI-83-35.

Olson, P.L., and Sivak, M.

1984a Joumal of the Illuminating Engineering Society, 13, 296-303. Discomfort glare from automobile headlights.

Olson, P.L., and Sivak, M.

1984b Glare and headlighting design. Society of Automotive Engineers, Paper No SAE-840047.

Olson, P.L., and Sivak, M.

1984c Human Factors, 26, 269-282. Glare from automobile rear vision mirrors.

Olson, P.L., and Sivak, M.

1984d Visibility problems in night-time driving. In: G.A. Peters and B.J. Peters (Eds), Automotive Engineering and Litigation, Vol 1. New York: Garland.

Olson, P.L., Sivak, M., and Egan, J.C.

1983 Variables influencing the night-time legibility of highway signs. Ann Arbor, Michigan: The University of Michigan Transportation Research Institute, Report No UMTRI-83-36.
Olson, P.L., Sivak, M., and Henson, D.L.

1981 Journal of Traffic Safety Education, 28.4, 20-22. Headlamps and visibility limitations in night-time traffic.

Olson, P.L., and Sivak, $M$

1986 Human Factors, 26, 91-96. Perception-response time to unexpected roadway hazard.

Olson, P.L., and Winkler, C.B.

1985 Measurement of crash avoidance characteristics of vehicles in use. Ann Arbor, Michigan: The University of Michigan Transportation Research Institute, Report No UMTRI-85-20.

Olson, P.L., Zimmer, R., and Pezoldt, V.

1986 Pavement edge drop. Ann Arbor, Michigan: The University of Michigan Transportation Research Institute, Report No UMTRI-86-33

Perel, M., Olson, P.L., Sivak, M., and Medlin, J.W. Jr

1983 Motor vehicle forward lighting. Society of Automotive Engineers, Paper No SAE-830567.

Post, D.V.

1978 Signal lighting system requirements for emergency, school bus, and service vehicles. Ann Arbor, Michigan: Highway Safety Research Institute, The University of Michigan, Report No UM-HSRI-78-55.

Schneider, L.W., Olson, P.L., Anderson, C.K., and Post, D.V. 1979 Identification of variables affecting driver seated position. Ann Arbor, Michigan: Highway Safety Research Institute, The University of Michigan, Report No UM-HSRI-79-47.

Sivak, M.

1978 Motor vehicle rear lighting and signaling: effects of spacing, position, intensity, and color. An appliedliterature review. Ann Arbor, Michigan: Highway Safety Research Institute, The University of Michigan, Report No UM-HSRI-78-8.

Sivak, $\mathbf{M}$.

1981a Accident Analysis and Prevention, 13,61-64. Human factors and highway-accident causation: some theoretical considerations.

Sivak, M.

$1981 \mathrm{~b}$ What a motorist can do to minimize the chances of being involved in an accident. Ann Arbor, Michigan: Highway Safety Research Institute, The University of Michigan, Report No UM-HSRI-81-37.

Sivak, M.

1983 Journal of Safety Research, 14, 93-99. Society's aggression level as a predictor of traffic fataiity rate.

Sivak, M.

1985 Ergonomics, 28, 1143-1153. Multiple ergonomic interventions and transportation safety.

Sivak, M., Conn, L.S., and Olson, P.L.

1986 Journal of Safety Research, 17, 13-22. Driver eye fixations and the optimal locations for automobile brake lights.

Sivak, M., Flannagan, M.J., Olson, P.L., Bender, M., and Conn, L.S.

1986 Evaluation of brake-lamp photometric requirements. Ann Arbor, Michigan: The University of Michigan Transportation Research Institute, Report No UMTRI 86-28. 
Sivak, M., Hill, C.S., Henson, D.L., Butler, B.P., Silber, S.M., and Olson, P.L.

1984 Archives of Physical Medicine and Rehabilitation, 65, 163-167. Improved driving performance following perceptual training of persons with brain damage.

Sivak, M., Hill, C.S., and Olson, P.L.

1984 International Joumal of Rehabilitation Research, 7, 389-398. Computerized video tasks as training techniques for driving-related perceptual deficits of persons with brain damage: a pilot evaluation.

Sivak, M., Hill, C.S., Olson, P.L., and Henson, D.L.

1981 Preliminary testing of techniques to improve driving performance of persons with brain damage via perceptual/cognitive training. Ann Arbor, Michigan: Highway Safety Research Institute, The University of Michigan, Interim Report No UM-HSRI-81-12.

Sivak, M., and Olson, P.L.

1982 Accident Analysis and Prevention, 14, 87-93. Nighttime legibility of traffic signs: conditions eliminating the effects of driver age and disability glare.

Sivak, M., and Olson, P.L.

1984 Night-time visual problems of elderly drivers. Presented at the First International Congress of Traffic Psychology and Highway Safety, Valencia, Spain, June 18-20.

Sivak, M., and Olson, P.L.

1985a From headlamp illumination to headlamp performance: A critical review of issues relevant to the Ford Motor Company DETECT model. Ann Arbor, Michigan: The University of Michigan Transportation Research Institute, Report No UMTRI85-2.

Sivak, M., and Olson, P.L.

1985b Transportation Research Record, 1027, 53-57. Optimal and minimal luminance characteristics for retro-reflective highway signs.
Sivak, M., Olson, P.L., and Farmer, K.M.

1981 High-mounted brake lights and the behavior of following drivers. Ann Arbor, Michigan: Highway Safety Research Institute, The University of Michigan, Report No UM-HSRI- $81-31$

Sivak, M., Olson, P.L., and Farmer, K.M.

1982 Perceptual and Motor Skills, 55, 594. Radar. measured reaction times of unalerted drivers to brake signals.

Sivak, M., Olson, P.L., and Green, P.

1986 International Journal of Vehicle Design, 7.5/6, 331337 . Human-factors methods in the design of vehicle components.

Sivak, M., Olson, P.L., Kewman, D.G., Won, H., and Henson, D.L.

1981 Archives of Physical Medicine and Rehabilitation, 62, 476-483. Driving and perceptual/cognitive skills: behavioral consequences of brain damage.

Sivak, M., Olson, P.L., and Pastalan, L.A.

1981 Human Factors, 23, 59-64. Effect of driver's age on night-time legibility of highway signs.

Sivak, M., Post, D.V., Olson, P.L., and Donohue, R.J.

1981 a Perceptual and Motor Skills, 52, 795-802. Automobile rear lights: effects of the number, mounting height, and lateral position on reaction times of following drivers.

Sivak, M., Post, D.V., Olson, P.L., and Donohue, R.J.

1981b Human Factors, 23, 231-235. Driver responses to high-mounted brake lights in actual traffic.

Sivak, M., and Soler, J.

1986a Traffic accidents in Spain and the USA: A crosscultural comparison of associated factors. Ann Arbor, Michigan: The University of Michigan Transportation Research Institute, Report No UMTRI-86-4.

Sivak, M., and Soler, J.

1986b Driver risk-perception in Spain and the USA. Ann Arbor, Michigan: The University of Michigan Transportation Research Institute, Report No UMTRI86-49. 